\title{
Interlacing Bloom's Taxonomy and E-Learning to Improve the Quality of English Class
}

\author{
Dr.K.Yugandhar \\ Associate Professor, Department of English \\ Dilla University, Dilla, Ethiopia \\ yogi.english@gmail.com
}

\begin{abstract}
Bloom's Taxonomy was formed under the leadership of educational psychologist Dr. Benjamin Bloom in order to promote higher forms of thinking in education, such as analyzing and evaluating, rather than just remembering facts (rote learning). The current trend in English language teaching in these days of digitized days is e-learning. It is based on blending multimedia computers and Internet with English language learning/teaching. E-learning describes the use of educational technologies and allows learners flexibility in choosing the time / place for learning. Blended learning has been extended to include e-learning integrating elearning into traditional methods of teaching. Against this background, the paper aims to focus on the paradigms and practices in interlacing e-learning with authentic materials and three domains of educational activities or learning - Knowledge, Attitude and Skills to upgrade communicative capacities of undergraduate students.
\end{abstract}

Keywords: English Language Teaching, Blended E-Learning, Bloom's Taxonomy, Authentic Materials, Collaborative Environment, Constructivist Learning.

\section{INTRODUCTION}

E-learning enables learners to navigate interactive, self-learning real-life material with the helping hand of the Internet at their own pace and path. Learners are provided with choice, control and interaction using computer as a tool to understand, learn and to use the language. As the class has no boundaries of place and time, learner can interact with the information to sharpen his/her language/communicative abilities according to his/her convenient place and time. The incentives of the updated version of the class are - autonomy, spirit of learning and using the language, acquiring the ability at one's own pace and method and the spontaneous feedback during the activities makes the learning faster. In Bloom's Taxonomy, the application level is where student moves beyond basic comprehension and actually begin to apply what they've learned.

Bloom's Taxonomy divides the way people learn into three domains. One of these is the cognitive domain, which emphasizes intellectual outcomes. The authors of the revised taxonomy emphasize dynamism using the following 'action words' to describe the cognitive processes by which thinkers encounter and work with knowledge.

- Remember

- Understand

- Apply

- Analyze

- Evaluate

- Create

\section{THEORY OF BLOOM'S TAXONOMY}

The Bloom Taxonomy theory is a basic theory that is rapidly used in cognitive learning created by an educational expert, namely Dr Benjamin Bloom. Bloom found that over $95 \%$ of the test questions students' encounter require them to think only at the lowest possible level - the recall of information. Bloom believed that education should focus on 'mastery' of subjects and the promotion of higher 


\section{Dr.K.Yugandhar}

forms of thinking, rather than an approach to simply transferring facts. Bloom's Taxonomy divides the way people learn into three domains that are cognitive, affective and psychomotor.

- Cognitive domain includes intellectual capability for example knowledge, or 'think'

- Affective domain includes feelings, emotions and behaviour for example attitude or 'feel'

- Psychomotor domain includes manual and physical skills for example skills, or 'do'

Cognitive domain is frequently used to evaluate students' performance through tests and valuation. There are six levels of thinking development for cognitive domain in Bloom Taxonomy starting from the simplest behaviour to the most complex. Bloom identified six levels within the cognitive domain, from the simple recall or recognition of facts, as the lowest level, through increasingly more complex and abstract mental levels, to the highest order which is classified as evaluation. The six levels of cognitive domain are illustrated as follows:

- Knowledge is the memorizing of previously learned material

- Comprehension is the capability to grasp the meaning of material

- Application refers to the ability to use learned material in new and concrete situations

- Analysis refers to the talent to break down material into its component parts so that its organizational structure may be understood

- Synthesis refers to the skill to put parts together to form a new whole

- Evaluation is concerned with the ability to judge the value of material for a given purpose

Bloom believed that education should focus on 'mastery' of subjects and the promotion of higher forms of thinking, rather than an approach to simply transferring facts and development process from one level to another. The intersection of a well-defined curriculum, appropriate and reliable assessments, and aligned instruction creates the necessary conditions for mastery learning - the promise of success for all students. These three conditions provide the foundation for mastery learning:

Curriculum- The course of study offered in an educational institution

Mastery learning does not focus on content, but on the process of mastering the learning outcome. This type of learning works best with the traditional content-focused curriculum, one based on well-defined learning objectives organized into smaller, sequentially organized units.

Instruction - An evaluation of knowledge or achievement

Strategy captures many of the elements of successful tutoring and the independent functionality seen in fast learners. In a mastery-learning environment, the teacher directs a variety of group-based instructional techniques and provides frequent and specific feedback by using diagnostic, formative tests, as well as regularly correcting mistakes students make along their learning path.

Assessment - The act or practice of imparting knowledge; a lesson

Teachers evaluate students with criterion-referenced tests rather than norm-referenced tests. Mastery learning ensures numerous feedbacks loops, based on small units of well-defined, appropriately sequenced outcomes.

Time to learn must be adjusted to fit ability. No student will proceed to a new level until basic prerequisite level is mastered. The incentives of e-class - autonomy, spirit of learning and using the language, acquiring the ability at one's own pace and method and the spontaneous feedback help the learners to achieve the desired proficiency.

\section{CONCEPT OF E-LEARNing}

An ideal English Language Teaching class aims improving Listening, Speaking, Reading and Writing skills and the four aspects - Grammar, Vocabulary, Spelling and Pronunciation. Every teacher in this digital era wants to improve the quality of the class by using the real life materials to improve the learners' language proficiency. E-class plays major role in facilitating the suitable authentic materials in digital format that can be used according to the needs of the teacher and the learner. The current trend in ELT - English Language Teaching is 'Integrative Computer Aided Language Learning' 
which is based on interlacing multimedia computers and Internet with English language learning. E-class room plays major role in providing the suitable materials and in applying appropriate methods by mediating the teacher and students in language learning. The class has no boundaries of place and time. Learner can interact with the information to sharpen his/her language/ communicative abilities according to his/her convenient place and time.

E-Learning is any teaching and learning form that uses electronic network for presenting the content and interaction. Comparatively, the method e-Learning is students and materials based while learning through the traditional method is based on a teacher. The traditional system needs more effort from a teacher as the knowledge contributor. However, via teaching a teacher is centred on a one way communication, which is less effective nowadays. Students and materials centred learning process requires students' participation and support from the selected material such as textbooks when learning. Teachers will facilitate the ambiance conducive for language acquisition.

\section{Pedagogical Theories and E-English Class}

Pedagogical effort in e-English class typically means adopting and adapting existing technologybased materials or learning environments to a specific course or learning curriculum. It is the pedagogically innovative environment that researchers investigate how technology-based learning affects the language acquisition process. The e-class is effective if only the pedagogical theories are applied into the facilities provided. The fundamental aspect of communicative language teaching approach is the communicative competence. The approach pays systematic attention to functional as well as structural aspects of language. A computer simulation used in the class possesses both instruction-oriented and fun-oriented features. Warschauer and Kern as under illustrate relationship between e-class developmental stages and the psychology of language learning:

\begin{tabular}{|c|c|c|c|}
\hline $\begin{array}{c}\text { Theories with in } \\
\text { Psychology of } \\
\text { learning }\end{array}$ & Behaviourism & Cognitivism & Socioconstructivism \\
\cline { 3 - 4 } $\begin{array}{c}\text { E-Class } \\
\text { Approaches }\end{array}$ & Structural & Cognitive & Interactional \\
\hline $\begin{array}{c}\text { Role of } \\
\text { Computers }\end{array}$ & $\begin{array}{c}\text { To provide unlimited drill } \\
\text { practice, tutorial, } \\
\text { explanation and } \\
\text { Corrective feedback }\end{array}$ & $\begin{array}{c}\text { To provide language } \\
\text { input and inferential } \\
\text { tasks }\end{array}$ & $\begin{array}{c}\text { To provide alternative contexts } \\
\text { for social interaction: to } \\
\text { existing discourse communities } \\
\text { and creation of the new ones }\end{array}$ \\
\hline
\end{tabular}

E-learning provides ideal climate for student-student and student-teacher interaction during the class. Students can take attention of the teacher from their places by switching a button to clarify a doubt while practicing the tape script or listening activity. Teacher can listen to any student and interact with student/s to guide them during the practice. Listening and pronunciation tests can also be conducted in the laboratory whereby only students' answers are recorded for later evaluation. Equal audibility, space to oneself, self-pacing, exampled pronunciation, recording for comparing with the best, recording the records, speaking test, effective monitoring, supporting role-plays and archiving for evaluation are the features of the laboratory that makes teaching learning more individualized, interactive, innovative and interesting. In spite of the setbacks like greater investments of money besides time and uncertainty of results in using audio tape-based language laboratory, it is still believed that integrating new technologies should be an important goal of language programs. But a goal of which the cost and complexity should not be underestimated.

Lorin Anderson, a former student of Bloom, revisited the cognitive domain in the learning taxonomy in the mid-nineties and made some changes, with perhaps the two most prominent ones being, 1) changing the names in the six categories from noun to verb forms, and 2) slightly rearranging them. The revised taxonomy categorizes the knowledge on the basis of these six cognitive processes and is used in the following types in cognition:

- Factual Knowledge

- Conceptual Knowledge

- Procedural Knowledge

- Meta cognitive Knowledge 
Cognitive support from authentic materials using e-learning tools is effectively used for the interaction of ideas among the learners. E-class plays major role in providing the suitable authentic materials in different levels as per the revised Taxonomy mediating the teacher and students in language learning. The class has no boundaries of place and time and learners can interact with the information to acquire and use communicative abilities and use the language as per the instructions of the teacher following the taxonomy.

\section{Communicative Behaviour in E-English Class}

Communication is a range of purposeful behaviour that is used with intent within the structure of social exchanges, to transmit information, observations, or internal status, or to bring about changes in the immediate environment. Nonverbal communication is defined as the process by which nonverbal behaviour is used, either singly or in combination with verbal behaviors, in the exchange and interpretation of messages within a given situation or context. Nonverbal cues may be acted subconsciously and reacted upon, regulating proximity, gestures, eye gaze and touch. Computer supported-training environment can be used as cognitive tool to analyze speech receptive behaviour to develop the same. Fostering of speech receptive behaviour improves the effectiveness and efficiency of training the communicative behaviour. Analysis of the learning goals in the domain of speech receptive behaviour leads to the following results:

$>$ A computer supported training environment which is designed to foster speech receptive behaviour has to support the de-automation of the behaviour by

- supporting the learner in bringing his / her own behaviour into consciousness

- decreasing the cognitive load caused by reflection.

$>$ The re-automation of communicative behaviour can be supported by

- associating the reflection of the learner's behaviour

- providing the learner with the opportunity to repeatedly exercise the changed or newly acquired behaviour.

Computer-supported e-class enables students to receive individualized instruction with appropriate blend of hands-on and hands-off approaches with extended applications in reinforcing classroom activities. The following five factors are identified which have been shown to be responsible for the success of the learning environment:

$>$ Describing the Subject: The accurate description of the subject matter allows the definition of learning goals and the identification of the kind of knowledge / skills that are to be learnt / acquired. This description leads to the learning goal of a differentiated understanding of communicative utterances. Further opportunities are to be provided to the learners to establish their digital skills.

$>$ Interlace Software into the Class: Software should not be used as an end in itself. Only the deliberated use of learning software in the service of instructional goals will lead to success (Kerres, 2000). Learners are to be given opportunities for self-reflection after facilitating easy-to understand instructions and good examples of using software. The use of software makes most sense if it is integrated into conventional forms of learning and teaching (Kerres, 2000).This is particularly the case with the training of soft skills because they consist of both individual cognitive and social interactive skills. The computer-supported training environment is integrated into a face-to-face course setting to develop speech productive and speech receptive behaviour.

> Authentic Learning Scenarios: A basic assumption of situated learning approaches is the authenticity of the learning scenario (Collins, (1989); Law, (2000). The context of learning should be similar to the context in which the acquired knowledge and skills are used in everyday life. The computer supported-supported environment is embedded into an authentic learning scenario. The analysis of conversational utterances is conducted on the basis of realistic conversational situations by video sequences. Collaboration and co-construction of knowledge is emphasized when the learners are using e-learning tools and resources.

$>$ Obligatory Participation: The learner can only profit from software, if he / she uses it. Thus, we do not consider it helpful, if the use of learning environment is voluntary. Particularly, if the computer supported training environment is embedded into a course setting, it is necessary to establish the same or a similar level of knowledge in all the learners. Several studies showed that the learning environment is successful in teaching a differentiated analysis of conversational 
utterances independent of the learners' motivation. E-learning tasks are to be built that facilitate effective ambiance for language acquisition that engage learners in meaningful communicative practice besides supporting them to notice and correct their errors.

$>$ Adaptability of the Software: No two soft skills trainings are same. It is important to emphasize different contents to adapt training to the needs / interests of the participants. Thus, it is necessary for a computer-supported learning environment, which is integrated into such training, to be adaptable to the special situation of training. Soft skills through software provide choice to the knowledge and interests of the learner. The teacher has the possibility to integrate different video sequences into the training environment and to switch on / off diverse instructional features as desired. Learners' comments on their use of e-learning tools and their suggestions are to be incorporated into the curriculum.

\section{Conclusion}

Bloom Taxonomy is widely used in this context as this theory is easy to understand and can be customized based on individual needs starting from the simplest behaviour to the most complex. It focuses on the application level is where student moves beyond basic comprehension and actually begin to apply what they've learned. It addresses various learners based on the way people learn into three domains. One of these is the cognitive domain, which emphasizes intellectual outcomes. In e-English class, the learners participate in various activities in face-to-face / online activities using their knowledge, comprehension and evaluation of the information they have got from the interaction with the materials. It is clear that the lower-order skills of knowledge, moderate evidence of the intermediate skills of comprehension and application and some evidence of the higher-order skills of evaluation and creativity are improved considerably among the students. Thus, the blending of e-learning with Bloom's Taxonomy is a learning-centered, co-operative and constructivist way of learning.

\section{REFERENCES}

Berado, S.A. "The Use of Authentic Materials in the Teaching of reading." The Reading Matrix 6.2. (2006).

Bloom, Benjamin S. Education Objective Handbook 1: Cognitive Domain. New York, USA: David Mc Kay Co., Inc. 1956.

Boyle, T. "Design for Multimedia Learning". London: Prentice Hall. 1997.

Breen, M.P.. "Learner contributions to task design" in C. N. Candlin and D. Murphy (eds.) Language Learning Tasks. Englewood Cliffs NJ: Prentice-Hall International. 1987.

Day, R.. Authenticity in the design and development of materials. In W. A. Renandya (Ed.), Methodology and materials design in language teaching. Singapore: SEAMEO Regional Language Centre. (2003).

Gilmore, A. "Authentic materials and authenticity in foreign language learning." Language Technology 40, 2007.

Herrington, J., Reeves, T. C., \& Oliver, R. A guide to authentic e-learning. New York: Rout ledge. 2010.

Lave, J., \& Wenger, E. Situated learning. Legitimate peripheral participation. New York: Cambridge University Press. 1991.

Tomlinson, B. Principles of effective materials development. In N. Harwood (Ed.), English language teaching materials: Theory and practice. Cambridge: Cambridge University Press. 2010.

\section{AUTHOR's BIOGRAPHY}

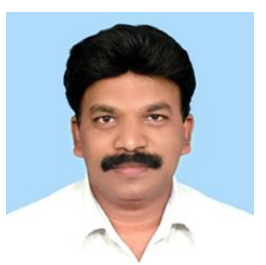

Dr.K.Yugandhar, Associate Professor of English has received Ph.D. in English from Jawaharlal Nehru Technological University, Hyderabad, India. He has been teaching English language and literature to graduate and post graduate students for the past seventeen years. Most of his research work focuses on interlacing technology with pedagogical concepts to improve the quality of Education in general and English Language Teaching in particular. He received credentials in ELT from Osmania University, Andhra University, Kakatiya University and Central Institute of English and Foreign Language, Andhra Pradesh, India. 